
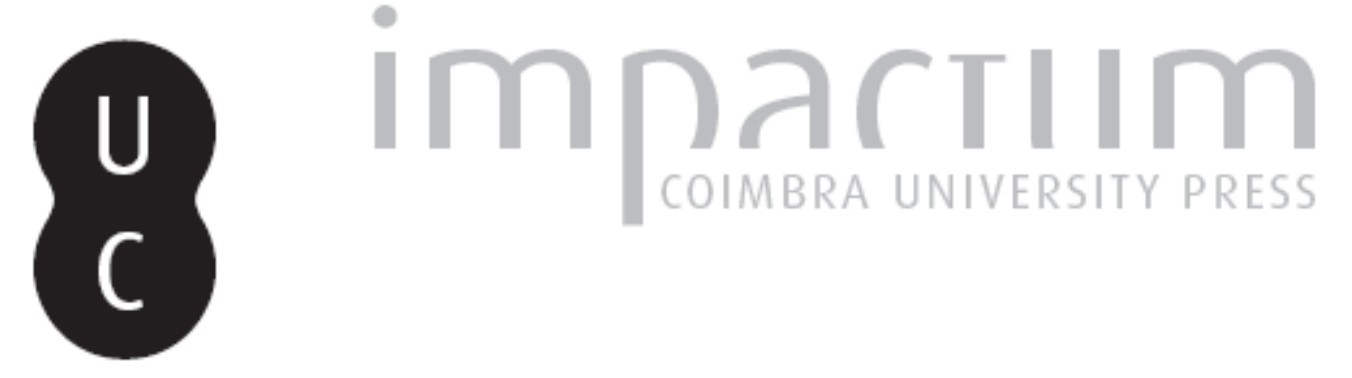

\title{
Margarita Torremocha Hernández y Alberto Corada Alonso (editores), La mujer en la balanza de la justicia (Castilla y Portugal, siglos XVII y XVIII)
}

Autor(es): Rey Castelao, Ofelia

Publicado por: Imprensa da Universidade de Coimbra

URL persistente:

URI:http://hdl.handle.net/10316.2/43250

DOI:

DOI:https://doi.org/10.14195/0870-4147_48_14

Accessed : $\quad$ 26-Apr-2023 15:01:52

A navegação consulta e descarregamento dos títulos inseridos nas Bibliotecas Digitais UC Digitalis, UC Pombalina e UC Impactum, pressupõem a aceitação plena e sem reservas dos Termos e Condições de Uso destas Bibliotecas Digitais, disponíveis em https://digitalis.uc.pt/pt-pt/termos.

Conforme exposto nos referidos Termos e Condições de Uso, o descarregamento de títulos de acesso restrito requer uma licença válida de autorização devendo o utilizador aceder ao(s) documento(s) a partir de um endereço de IP da instituição detentora da supramencionada licença.

Ao utilizador é apenas permitido o descarregamento para uso pessoal, pelo que o emprego do(s) título(s) descarregado(s) para outro fim, designadamente comercial, carece de autorização do respetivo autor ou editor da obra.

Na medida em que todas as obras da UC Digitalis se encontram protegidas pelo Código do Direito de Autor e Direitos Conexos e demais legislação aplicável, toda a cópia, parcial ou total, deste documento, nos casos em que é legalmente admitida, deverá conter ou fazer-se acompanhar por este aviso.

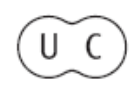




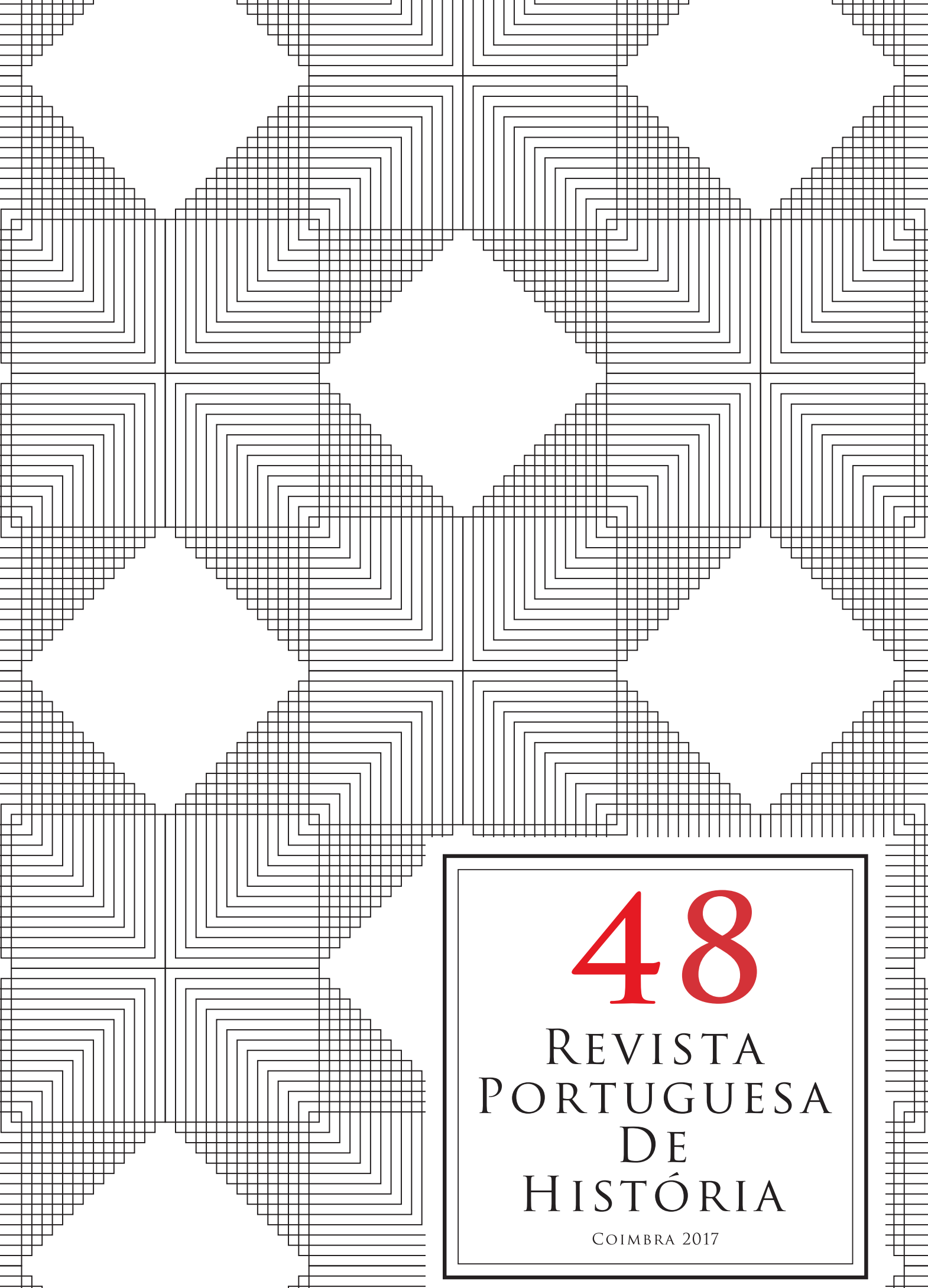




\section{Recensões}

\section{Margarita Torremocha Hernández y Alberto Corada Alonso (editores), La mujer en la balanza de la justicia (Castilla y Portugal, siglos XVII y XVIII). Valladolid, Castilla Ediciones, 2017, 221 p.}

En los últimos años Margarita Torremocha ha puesto su nombre en la portada de varias publicaciones sobre temas relacionados con las mujeres y la justicia, el "delito en femenino", entre las que destacan la que editó en 2015 con Isabel Drumond Braga (As mulheres perante os tribunais do Antigo Régimen na Península Ibérica, Coimbra, 2015) y el monográfico por ella coordinado de la revista italiana Historia et ius de 2016, por solo citar las más recientes. Junto con otras muchas aportaciones propias y de jóvenes investigadores, como Alberto Corada Alonso, co-editor de la que comentamos, se puede decir que en torno a Margarita Torremocha se ha formado un núcleo de investigación innovador y original centrado en los estudios de género desde la perspectiva judicial. Sus señas de identidad son su capacidad de vincular el análisis social más vanguardista -relacionado con la violencia y la judicialización de los conflictos- con el aparato de justicia, las instituciones de poder y de control social y las interpretaciones de la moral pública y social de la Edad Moderna, y por el dominio metodológico de las fuentes judiciales, cuya dificultad es bien conocida, de ahí el retraso de su empleo entre los modernistas.

El libro reúne ocho trabajos que tratan de conflictos de diversa índole, civiles, criminales, eclesiásticos, atendidos en tribunales y jurisdicciones diferentes -Chancillería de Valladolid y otros juzgados reales, concejiles, Inquisitoriales, del fuero de Marina, etc.-, en los que aparecen mujeres del común de Sevilla, León, Ferrol o Valladolid o monjas de potentes monasterios de Castilla -el de las Huelgas de Valladolid- o de Portugal -las del monasterio de San Bento de Cástris-. Todo lo cual da a la obra una diversidad de enfoques y de presencias femeninas, siempre bajo la perspectiva de "la mujer que se defiende y defiende lo suyo ante los tribunales" y de que "la justicia actuó contra ellas sin miramientos" 
y a veces con enorme rigor, de modo diferente a los hombres, como señala Margarita Torremocha en la introducción.

El capítulo de Margarita Torremocha es el que aborda más de cerca la dimensión institucional, en este caso "Galeras o cárceles de mujeres: el otro penitenciarismo de la Edad Moderna" (p. 51-74), reflexionando sobre el vacío teórico al respecto en la España moderna y aportando un agudo análisis de aquellos textos que sí se ocuparon de la cuestión femenina: los de la madre Magdalena de San Jerónimo (1608) y los de los juristas Antonio González Yebra (1784) y Luis Marcelino Pereira (1796). Recordemos que la autora lo es también de un libro reciente sobre la galera de Valladolid, en el que se aborda no solo la teoría sino su aplicación en esa institución de reclusión, una obra que consideramos completa y un modelo a seguir en el estudio de otras galeras y casas de reclusión (De la mancebía a la clausura. La Casa de Aprobación de Magdalena de San Jerónimo y el convento de San Felipe de la Penitencia. Valladolid, siglos XVI-XIX, ediciones de la universidad de Valladolid, 2014).

Los discursos normativos están presentes también en el capítulo firmado por Juan José Iglesias Rodríguez ("Conflictos y resistencias femeninas. Mujeres y justicia en la España Moderna”, p. 13-50), en el que se presenta un elenco de casos referidos a mujeres andaluzas, inmersas en conflictos surgidos en la intimidad de los espacios familiares o de otros extra-familiares y menos "santos", que permiten el autor hablar con fundamento del rigor aplicado a las mujeres, pero también de que ellas dieron muestras de disconformidad, disidencia, resistencias, "reafirmaciones personales dentro de un mundo que intentaba ser severamente disciplinado por el poder establecido". No es una conclusión muy diferente a la que llega el capítulo de Alberto Corada Alonso ("La mujer y el divorcio en la justicia real ordinaria a finales del Antiguo Régimen”, p. 74-109), ya que en la mayoría de los casos que estudia-vistos en la Chancillería de Valladolid, aun tocando los divorcios a los tribunales eclesiásticos-fueron las mujeres quienes iniciaron los procesos ante la justicia, movidas por la necesidad de defender sus intereses económicos; el autor pone a la luz que cuando eran los demandantes eran hombres, les importaban más las cuestiones relacionadas con la defensa de su honra, valorada casi como la vida. Acudir a la justicia del rey era un modo de conseguir la resolución de problemas procesales, asegurar los derechos de los litigantes y dilucidar los aspectos civiles, que solían ser económicos.

Los capítulos en los protagonizados por mujeres encerradas en los claustros religiosos son los de María Herranz Pinacho y de Antónia Fialho Conde. El primero, titulado "Mujeres fuera del coro, las religiosas de las Huelgas de Valladolid en los pleitos de la Real Chancillería" (p. 133-156), se ocupa de la 
presencia de este cenobio en la actividad judicial mediante el análisis de cuatro pleitos y once ejecutorias de entre 1555 y 1632 en los que las monjas trataban de defender sus derechos en la herencia de sus familias, a la que en teoría renunciaban al entrar en religión pero de la que recibían dotes y alimentos. El segundo lleva por título "O exercício do poder a partir da clausura: o mosteiro femenino de S. Bento de Cástris (Portugal) no contexto pós-tridentino" (p. 157-180) y aborda también las tensiones entre esa casa y las familias de sus componentes en la gestión de las herencias y bienes vinculares de las religiosas, revelando un comportamiento muy semejante al del caso vallisoletano. Es un tema hasta ahora menos estudiado de lo que debiera, ya que por lo general se estudian los conflictos de las instituciones, no los de sus habitantes.

María José Pérez Álvarez se ocupa de los problemas de competencia judicial en el ámbito leonés y de su encabalgamiento a la hora de arbitrar conflictos en los que las mujeres aparecen como víctimas de ultrajes. Su fuente fundamental son en este caso los poderes notariales, lo que es muy loable por la escasez de trabajos que los empleen, cuando son esenciales para observar las fases previas al inicio de los pleitos. Esto permite a la autora diferenciar la tipología de conflictos según el estado civil de las mujeres y poner de manifiesto que mientras las solteras se ven implicadas en un 74,4\% de los casos en problemas por relaciones sexuales ilícitas, las otras litigaban por cuestiones de herencia y de endeudamiento ("Mujeres y conflictividad judicial en el León del siglo XVIII", p. 111-132). Un planteamiento parecido en su enfoque, esto es, primero el marco competencial y luego los conflictos, es el que sigue Alfredo Martín García ("Transgresiones femeninas, violencia y conflicto en la jurisdicción de Marina del Departamento de Ferrol a finales del Antiguo Régimen", p. 197-221), un capítulo sobre una villa portuaria convertida en 1726 en capital del Departamento Marítimo del Norte, lo que cambió su composición social y motivó un desaforado crecimiento demográfico a cuenta de una inmigración masculina, sometida en su mayor parte al fuero militar de Marina. La peculiar y dura situación de las mujeres en esa ciudad, muchas de ellas dedicadas a profesiones al borde de la marginalidad cuando no directamente en esta, generó una intensa conflictividad que es estudiada el autor empleando las numerosas demandas presentadas ante el tribunal de Marina ferrolano, analizando su tipología según el estado civil de las mujeres.

Para terminar, Isabel Drumond Braga trata de una cuestión relevante en su capítulo titulado "Género e confisco inquisitorial no Portugal moderno: da legislação à prática” (p. 181-196), en el que se expone la legislación portuguesa sobre los bienes de los presos, en su mayoría cristianos nuevos acusados de judaísmo, comprobando su aplicación a través de varios casos que afectaron a 
mujeres, algunas de ellas viudas que habían mantenido las actividades de sus maridos y que eran despojadas de sus bienes.

En la introducción del libro que comentamos, Margarita Torremocha indica que se ha decantado por un método cualitativo y por el análisis pormenorizado de los procesos y de otras fuentes -en especial, las notariales - para acceder a "la figura social de la delincuente en femenino" y detectar si, más allá de "un modelo de ser en lo femenino defendido por la Iglesia tridentina" existieron desviaciones de las identidades asignadas a las mujeres. No faltan cifras, sin embargo, no en vano son estas las que permiten establecer comparaciones y medir impactos. Esta combinación de fuentes, métodos y enfoques sociales diversos es lo que hace de esta obra una valiosa aportación, que se suma a las que ya hemos indicado.

Ofelia Rey Castelao

Faculdad de Geografía e Historia Universidade de Santiago de Compostela ofelia.rey@usc.es 